\title{
EFFECT OF METAL LOADING ON FOLDED SHEET MESOPOROUS MATERIAL
} (Me/FSM-16)

\author{
Maged Samir Ghattas* \\ Catalysis Department, Refining Division, Egyptian Petroleum Research Institute (EPRI). \\ Nasr City, Cairo, 11727, Egypt \\ (Recaived: 3 September 2006)
}

ABSTRACT

Folded sheet mesoporous material FSM-16 has been synthesized and loaded with 3, 6 \& 9 wt 5 of iran, copper ar sivivor. The powder $X$-ray diffraction and $N_{2}$ sorption characterizabions show that the parant FSM-16 and the prepared nine catalysts have wet-ardered hexagonet mesostructures. However, partial loss of eryttalinity is only observed in catalysts containing 6 and 9 wt \% iron. BET surface aroa pare volume and pore diameter, d (100) spacing and average crysta size values decreased for al the catalysts containing $3 \mathrm{wt} \%$ metal the decrease is in the order $F_{0}<\mathrm{Cu}<\mathrm{Ag}$. According to temperalure programmed reduction, different metal pheses are detected. in infrared spectra, band's at $1637,955,800$ and $620 \mathrm{~cm}^{-4}$ are greatly affected by mefal loading and a new band is only observed at $1385 \mathrm{~cm}^{-1}$ in the metalFSM-16 catalysts.

Key Words: Mesoporous materials; FeFSM-16; CuFSM-16; AgFSM-16; physicochemical properties; Metal bading.

\section{INTRODUCTION}

FSM-16 [1] is a mesoporous silicate material which has an ordered one-dimensional large pore system with highly specific surface area similar to the mesoporous silicate MCM-41 reported by Kresge et al. [2]. FSM-16 is synthesized from crystalline single-layered poly silicate kanemite $\left(\mathrm{NaHSiO}_{5} \cdot 3 \mathrm{H}_{2} \mathrm{O}\right.$ ) with aqueous solutions of organic surfactant molecules, such as alkyttrimethylammonium ion that serves as templates for the formation of the pores. Removing the organic fractions gives porous silica with uniform nano-scale pores. Chen ef al. [3] reported that MCM-41 and FSM-16 are formed by different mechanisms and the material derived from kanemite had higher thermal and hydrothermal stability than MCM-41.

These new mesoporous silicate materials attract wide attention as catalysts and catalyst supports. Some attempts have been made to enhance the activity and physico-chemical properties of these materials by certain modes, for instance, the isomorphous substitution of heteroatom for silicon in framework position, ion-exchange with metal ions and impregnation of metal salts solutions [4-10].

In other work [11], the catalytic activity of the iron, copper and silver supported on FSM-16 catalysts was studied toward the dehydrogenation and dehydration of methanol.

The present work dealt with the effect of metals loading that have different ionic radii on the mesoporosity of the FSM-16 material.

\section{EXPERIMENTAL.}

\section{Preparation}

The parent mesoporous silica of the FSM-16 type was synthesized by standard procedure [12].

Iron, copper and silver impregnated FSM-16 (Fe/FSM-16, Cu/FSM-16 and Ag/FSM-16) were prepared by impregnating the synthesized FSM-16 with an aqueous solution of a prescribed concentration $(3,6,9 \mathrm{wt} \%$ metal) of the metal nitrate (Aldrich, 99\%); the slurry was stirred vigorously for $15 \mathrm{~min}$. followed by the evaporation of excess water at $77^{\circ} \mathrm{C}$. The samples were dried at $110^{\circ} \mathrm{C}$ overnight, and calcined at $250^{\circ} \mathrm{C}$ for $4 \mathrm{~h}$ in dried air stream.

"Tet no $+2.012-417.3366 ;$ Fax $+2.02-274-7433$, Evmal mageprigyahoo com 


\section{Characterization}

The XRO patterns were obtained using a Shimadzu XD-3A powder difractometer employing CuKa radiation, Ni-filter and general area detector.

A temperature programmed reduction system was manually constructed. Samples of 20 $\mathrm{mg}$ were used. The flow rate of the $\mathrm{H}_{2}-\mathrm{N}_{2}$ mixture $(2: 20 \mathrm{v} / \mathrm{V})$ was $22 \mathrm{~cm}^{3} \mathrm{~min}^{-1}$. The temperature was raised at a programmed rate of $10^{2} \mathrm{C} \mathrm{min'1.} \mathrm{A} \mathrm{themal} \mathrm{conductivity} \mathrm{cell}$ detected the hydrogen consumption from the reactant stream.

The texture characteristics of parent FSM-16, iron, copper and silver loaded FSM-16 catalysts were determined by standard $\mathrm{N}_{2}$ adsorption isothems at $-196{ }^{\circ} \mathrm{C}$. Pore size distribution and pore volume were calculated by the $\mathrm{BJH}$ method. These analyses carried out on a Micrometrics ASAP 2010 automatic analyzer.

FTIR spectra were recorded on a Prospect FT-IR. Midac Corp., USA, and model 1997. equipped with a diffuse reflectance cell using the $\mathrm{KBr}$ disc technique.

Elemental analysis of the different metal (iron, copper and silver) was performed by the inductively coupled plasma atomic emission spectrometry, using ICP-AES Shimadzu ICPS7500 (Japan). These Analyses were carried out in the Catalysis and Surface Chemistry Lab. Fac. Eng.. Seoul Nat'l Univ., Seoul, South Korea.

\section{RESULTS AND DISCUSSION}

\section{Powder X-ray diffraction}

$\mathrm{X}$-ray diffraction patterns of the parent and $\mathrm{Fe}$, Cu and $\mathrm{Ag}$ modified FSM-16 are presented in Fig.1. The presence of four lines at $2 \theta=2-10$ for all samples indicates the presence of hexagonal array in these materials.

The preservation of small angles $x$-ray diffraction after the copper and siver loading Fig. 1 (B and C) is an indication for the absence of structural collapse of silica support during the sample preparation. However, the d spacing $(100)$ becomes relatively broader for catalysts containing 6 and $9 \mathrm{w} \%$ Fe Fig. 2A, whilst the other peaks are not very clear. This indicates that there is a partial loss of crystallinity of modified samples after iron loading.

The observed decrease in the line intensity after the impregnation especially of high ordered reflections at d spacing (100) can be ascribed to an overall decrease in the electron density difference between the silica wall and the pore due to the distribution of the metal species within the support pore system [10]. This is greatly observed for catalysts containing 6 and $9 \mathrm{~m} \%$ Fe (Flg. 1A).

No additional characteristics of crystalline metal oxides for iron, copper and silver were observed in XRD pattern (not shown); indicating the presence of highly dispersed metal oxide particles [10].

The sharp decrease in intensity of line at $(100)$ for the FerFSM-16 catalysts (Fig.1A) in comparison to Cu/FSM-16 (Fig.1B) and Ag/FSM-16 (Fig.1C) catalysts may be attributed to the presence of iron ions within the hexagonal array according to its smaller ionic radius 0.63 $\mathrm{A}$ than that of $\mathrm{Cu}$ ions $=0.71 \mathrm{~A}$ and $\mathrm{Ag}$ ion $=1,08 \mathrm{~A}$. So that the larger silver ions are present in the outside of the hexagonal pore system and the intensity of their $x$-ray reflection is almost not changed greatly as in the parent FSM-16.

The unit cell parameter $\alpha_{0}$ of the different catalyst samples is calculated from the peak with $h k J=100$ by the formula $\alpha_{0}=2 d_{r a d} / \sqrt{3}[9]$. The loading of different type of transition metals (Fe, Cu and $\mathrm{Ag}$ ) on the FSM-16 parent is reduces the $\alpha_{0}$ value as shown in table 1. 


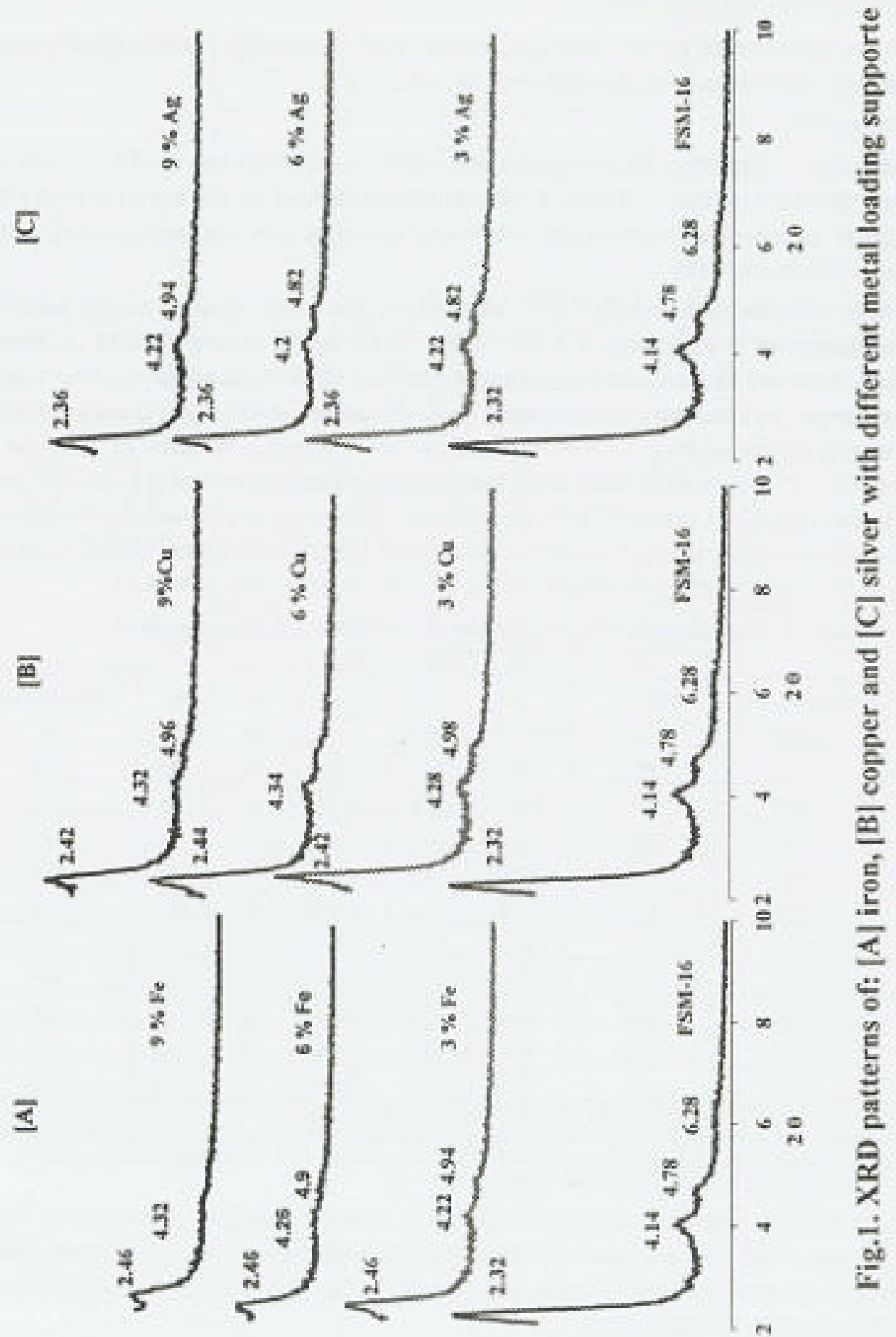


The lowering of ao value of all catalysts prepared atter metal loading, compared to that of parent material (Table1), indicates that the metal ions are present in the extraframwork and not incorporated in the FSM-16 silica.

At the same time the larger $\alpha_{0}$ value was observed for the sample containing silver ions than copper and iron ions according to the ionic radius of each.

\section{Texture Properties}

The $\mathrm{N}_{2}$ adsorption - desorption isotherms of parent material (FSM-16) and the $\mathrm{Fe}, \mathrm{Cu}$ and $\mathrm{Ag}$ loaded over FSM-16 (Fig. 2 A) is a type IV with H4 hysteresis loop as defined by IUPAC [18]. which is typical for mesoporous materials with hexagonal array that has large pore size with narrowed size distribution [19].

The sudden increase of the amount of $\mathrm{N}_{2}$ adsorbed is due to the capillary condensation in mesoporous observed in the range of $P_{d} P=0.27 \sim 0.48$ for the parent FSM-16. A similar behavior was observed for iron, copper and silver modified FSM-16 catalysts at a little higher and a wider range. The capillary condensation region becomes shallow and greatly affected as metal loading increases from $3-9$ wt $\%$ metal and as ionic radius of element decrease in this manner $\mathrm{Fe}<\mathrm{Cu}$. In contradiction, the adsorption-desorption isotherms Fig. $2 \mathrm{~A}$ and pore size distribution Fig. 2B of silveriFSM-16 are partially affected by silver loading on FSM-16. This behavior was clearly observed in the constancy of the pore diameter, $d(100)$ spacing. average unit cell and the wall thickness by increasing the silver loading (Table 1).

Table 1. Physicochemical properties of the parent FSM-16 silica and supported with iron, coppes and silver catalysts

\begin{tabular}{|c|c|c|c|c|c|c|c|c|}
\hline & $\begin{array}{l}\text { Metal ceotent } \\
\qquad(\mathrm{nt} \mathrm{H})^{\circ}\end{array}$ & 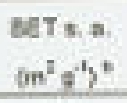 & $\begin{array}{c}\text { P. V. } \\
\left(\cos ^{3} \theta^{-1}\right)^{2}\end{array}$ & $\begin{array}{l}\text { PO } \\
\left(A_{0}\right)^{\prime}\end{array}$ & owdr" & $\begin{array}{l}\text { Chat } \\
\text { (A) }\end{array}$ & $\begin{array}{l}\pi_{4}^{\prime} \\
\text { (A) }\end{array}$ & $\begin{array}{c}\text { Wall thickness a } \\
\text { (h) }\end{array}$ \\
\hline $\mathrm{FSM}-16$ & - & 921 & 1009 & 246 & 2.181 & 39 & 439 & 193 \\
\hline 2450 & 2.92 & 702 & 9.797 & $22 \mathrm{a}$ & 0.121 & 26. & 30 & 22 \\
\hline 6SFFe & 5.88 & 703 & 0.688 & 24 & 0.131 & 26 & 30 & 6. \\
\hline gafe & 7.91 & 652 & 2.633 & 242 & 0.004 & 30 & 34.6 & 10.4 \\
\hline 3400 & 2.92 & 765 & Q.77\% & 234 & $0.15 ?$ & 33 & 38.1 & 14.7 \\
\hline 6esca & 5.93 & 624 & 0.723 & 20.4 & 0.130 & 26 & 30 & 6.6 \\
\hline 9xces & 32 & cos & 0.653 & 22.8 & 0.160 & 33 & 35.1 & 153 \\
\hline $3 \%{ }^{3}$ & 2.96 & 802 & 0.831 & 23.2 & 2.207 & 36 & 41.6 & 18.4 \\
\hline $64 x$ & 5.05 & 702 & 0.712 & 23.2 & 0.50 & 36 & 41.6 & 18.4 \\
\hline SHA & 8.68 & 650 & 0.783 & 23.2 & 0.170 & 36 & 41.6 & 18.4 \\
\hline
\end{tabular}

Thebl content data from ICP-AES, Surtace arva calculated fram BET equation, 'Pore velume calculated from the adsorptian branch of the ischerm at P/Po-1, " Pere diameler calculated from the dasorption branch of the isctherm according to BJH method, "Vake corresponding to the maxmum pore radius in Fig 3,' Calculated using formula $\omega_{0}=2 d_{100} / \sqrt{ } 3$ freen $\times R D[9]$, "Ditference between $a_{6}$ and pore dameter.

Both BET surface area and pore volume (Table 1) were decreased and changed by silver loading because silver ions occupied the surface outside the hexagonal pore system. But in other cases, metal ions are present inside and outside the hexagonal pore much more for iron catalysts than in case of copper ones.

In case of iron catalysts, pore diameter and pore size distribution were affected greatly by the penetration of iron ions inside the pore system as iron content increases (Table 1 and Fig. 2B).

In conclusion, the texture properties (BET surface area and Pore system) was affected by loading of different transition metal as in the following manner $\mathrm{Fe}>\mathrm{Cu}>\mathrm{Ag}$. This is greatly dependent on the ionic radius of each metal ion (Fig. $2 A$ and B). 

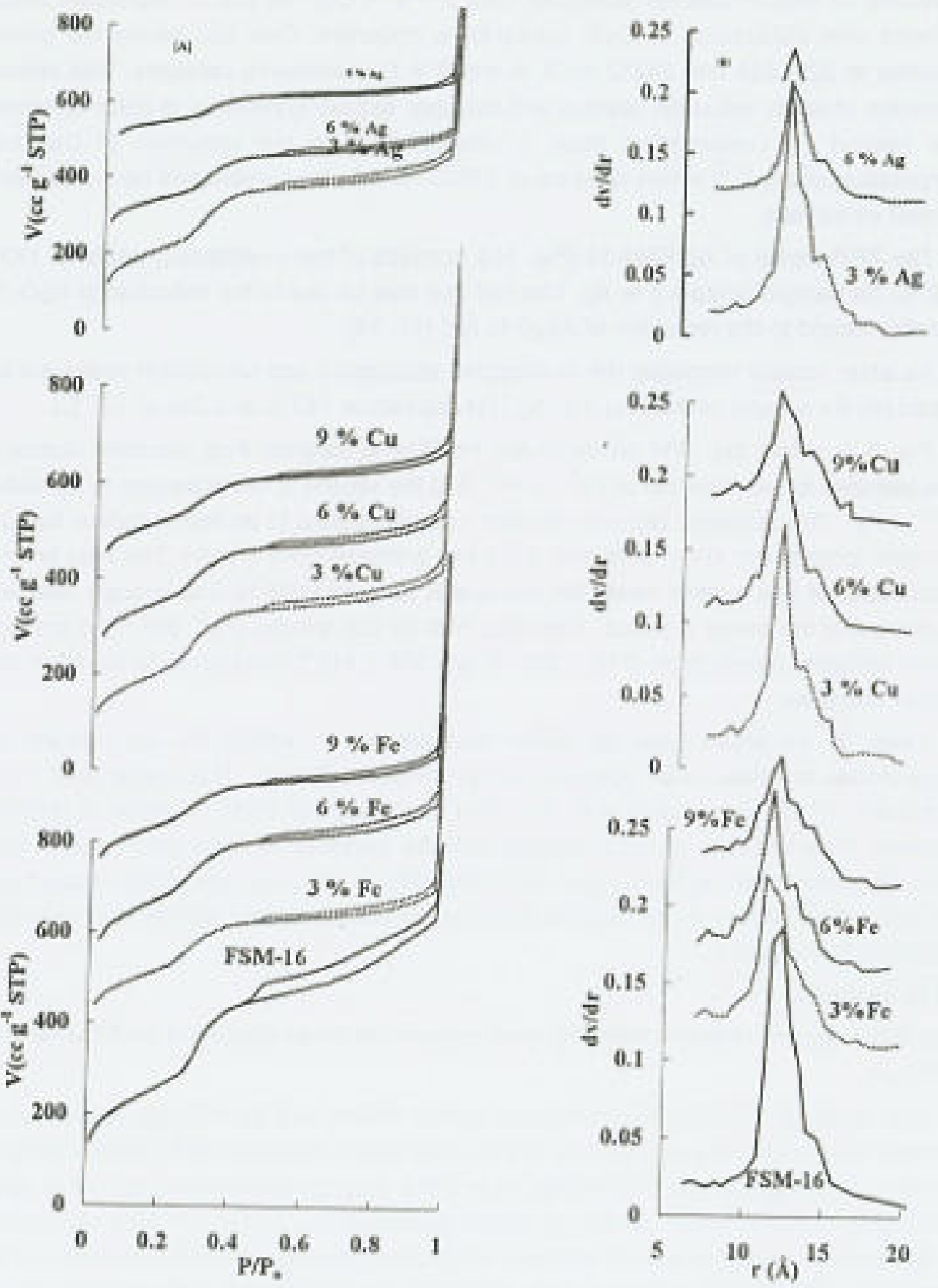

Fig. 2. Adsorption-desorption isotherms $[A]$ and pore size distribution [B] for iron oxide, copper oxide and silver oxide supported on FSM-16 


\subsection{Temperature Programmed Reduction Analysis (TPR)}

TPR profiles of Fe/FSM-16, Cu/FSM-16 and Ag/FSM-16 catalysts are reported in Fig. 3.

Fig. $3 \mathrm{~B}$ consists of two peaks, one appear at $270^{\circ} \mathrm{C}$, for sample containing $3 \% \mathrm{Cu}$, which is assigned to the reduction of $\mathrm{Cu}^{2 *}$ ion (low temperature peak) [13]. The intensity of this peak increases as copper content increases from $3-9 \% \mathrm{Cu}$ that can be explained assuming a different size distribution of CuO crystallite is observed. One can detect the presence of shoulder at 229,239 and $245^{\circ} \mathrm{C}$ for 3,6 and $9 \% \mathrm{Cu}$ containing catalysts. This indicates the formation of easily reducible species and assigned to $\mathrm{CuO}$ crystallites of different dimensions. The second $\mathrm{H}_{2}$ consumption peak is characterized to the reduction of $\mathrm{Cu}^{+}$ion (high temperature peak) [13] which appears at $316^{\circ} \mathrm{C}$ for $9 \% \mathrm{Cu}$ sample and becomes faint as $\mathrm{Cu}$ content decreases.

The TPR profile of Ag/FSM-16 (Fig. 3C), consists of two overtapping peaks at $143{ }^{\circ} \mathrm{C}$ and $168^{\circ} \mathrm{C}$, for sample contain $3 \% \mathrm{Ag}$. The first one may be due to the reduction of $\mathrm{AgO}_{2}$ to $\mathrm{Ag}_{2} \mathrm{O}$ and the second to the reduction of $\mathrm{Ag}_{2} \mathrm{O}$ to $\mathrm{Ag}^{\circ}[13,14]$.

As silver content increases the overlapping disappears and two distinct peaks are detected especially for sample containing $9 \% \mathrm{Ag}$ (1st appears at $162^{\circ} \mathrm{C}$ and 2 nd at $177^{\circ} \mathrm{C}$ ).

Fig. 3 A shows the TPR profile of the Fe/FSM-16 catalyst. First reduction consumption is characterized to the reduction of $\mathrm{Fe}^{3+}$ to $\mathrm{Fe}^{2}$ and the second is comesponding to the reduction of $\mathrm{Fe}^{2 *}$ to $\mathrm{Fe}^{\circ}$. The reduction behavior of these catalysts seems to be less reductive than the other catalysts (copper and silver catalysts). Each has a litte $\mathrm{H}_{2}$ consumption. This may be due to the stablization of iron cations inside the hexagonal array of FSM-16 and strongly held with silica framework of the parent material. Therefore, both of iron species ( $\mathrm{Fe}^{\mathrm{j}}$ and $\mathrm{Fe}^{2}$ ) are reduced at higher reduction temperature $\left(318-323^{\circ} \mathrm{C}\right.$ and $\left.398-410^{\circ} \mathrm{C}\right)$ compared to the other species of copper and silver.

There is no broad peak at higher temperature $\left(>450^{\circ} \mathrm{C}\right)$ for all catalyst samples. corresponds to metal oxide species (silicate or hydrosilicate). This means that there is no interaction of the iron cation with the silica framework of FSM-16 which is difficull to be reduced. This behavior is accompanied with the presence of large pore size of the parent FSM-16. Since some authors $[15-17]$ stated that as the pore size of the support increases the interaction of iron oxide species with the support becomes weaker and reduces at low reduction temperature.

\section{FTIR analysis}

The FTIR spectra of parent FSM-16, iron, copper and silver supported on FSM-16 are shown in Fig. 4.

The band at $1637 \mathrm{~cm}^{-1}$ is associated with $\delta \mathrm{SiO} \cdot \mathrm{H}$, and its intensity increases as metal content increases. This may be due to the metal nitrate precursor is highly oxidizing agent, it oxidizes Si-OH group into SiO-H [20], since FSM-16 properties resembles that of amorphous silica [21], contains large number of silanol groups at the surface of their channels. As the metal content increases (due to increase of metal nitrate precursors) the intensity of this peak increases. The same behavior was observed for Ni/FSM-16 and Co/FSM-16 catalysts containing different nickel and cobalt contents $[5,22]$.

The band at $1385 \mathrm{~cm}^{-1}$ is ascribed for the metal oxide not for the support. This band may be attributed to the vibration spectra of $\mathrm{Me}-\mathrm{O}$ or $\mathrm{MeO}-\mathrm{OH}$ present in the certain bond linkage with the framework of FSM-16. This band is closely identical for that present in Ni/FSM-16 [5] and Ni/montmorillonite K10 [23] 

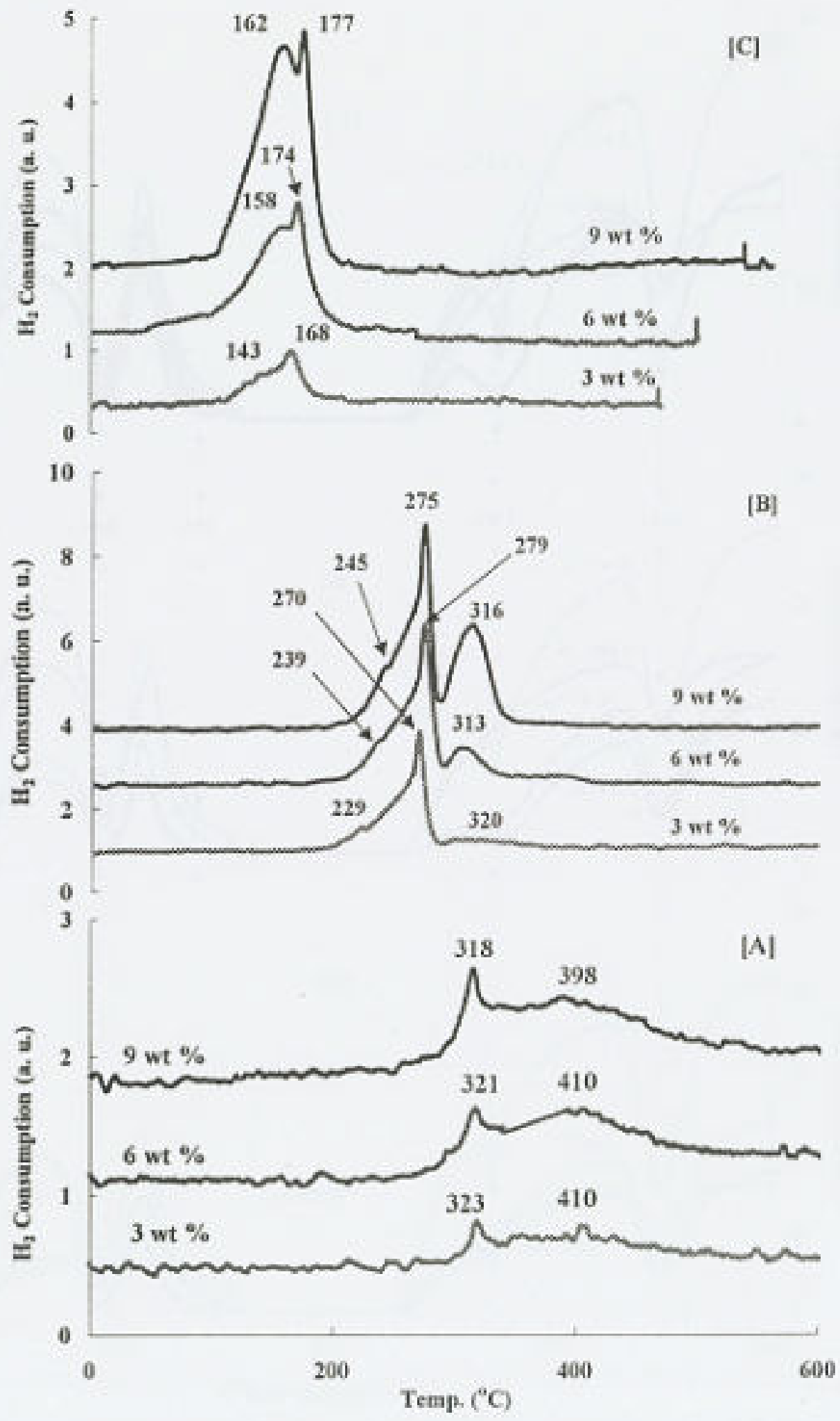

Fig.3. TPR of metal oxide/FSM-16 catalysts:[A] iron oxide /FSM-16, [B] copper oxide/FSM-16 and [C] silver oxide /FSM-16. 
20

Effect of metal loading

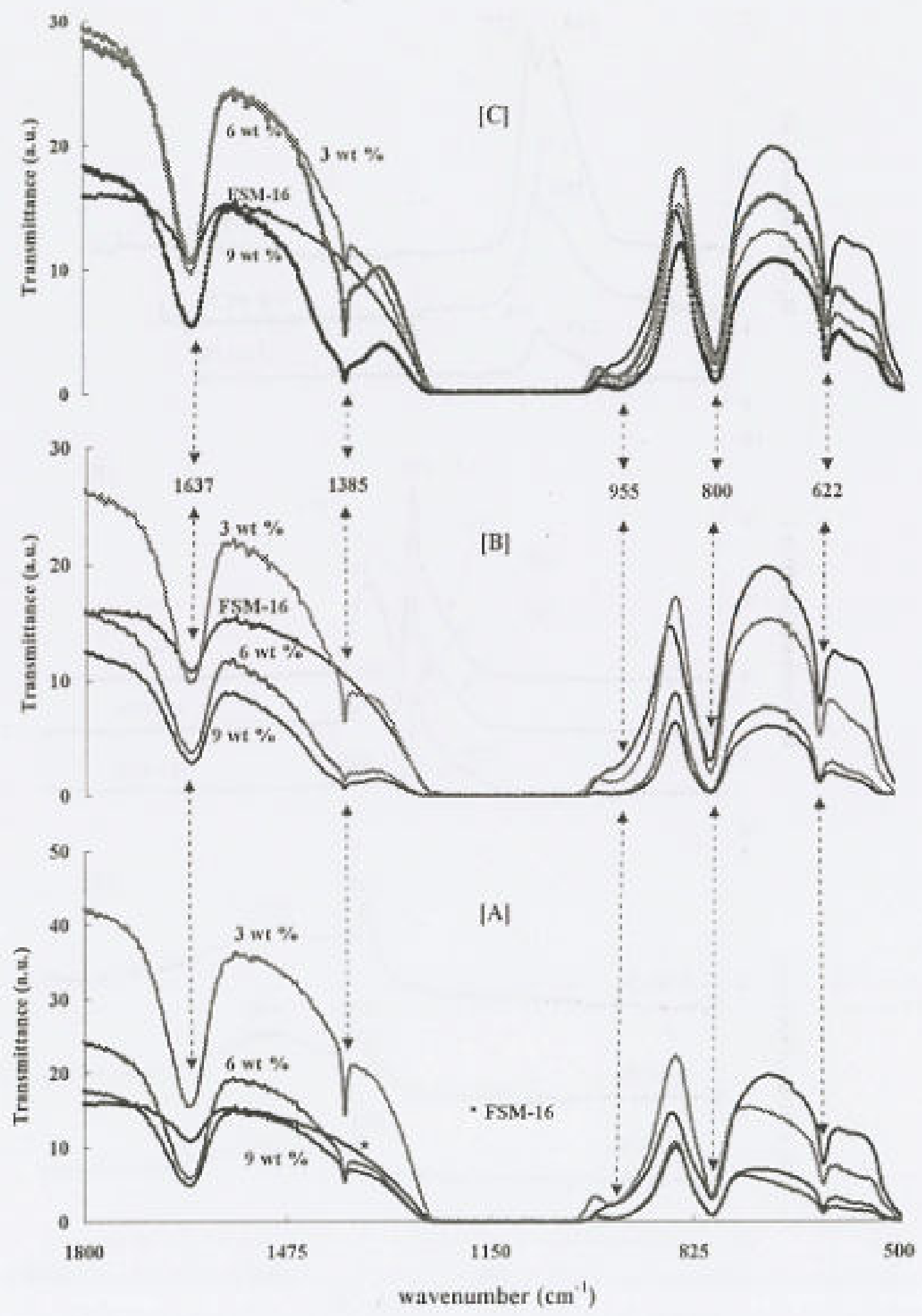

Fig.4,FTIR spectra of $[A]$ iron Oxide, $[B]$ copper oxide and $[C]$ silver oxide supported on FSM-16

Delta J. Sci. $2006,30.21-30$ 
Some authors $[24,25]$ reported that the weak band at $955 \mathrm{~cm}^{-1}$ is attributed to the stretching vibration of Si-O of silanol group (E Si-OH) in MCM-41, it disappears by silicification. On the other hand, this peak was assigned to the bending vibration of Si-O-Me in metal incorporated MCM-41 [26 - 30]. Schwarz et al. [31] also reported that the band at $\sim 960$ $\mathrm{cm}^{-1}$ is attributed to a superposition of the isolated Si-O-Ti stretching and it is hydrolyzed to $\mathrm{SiOH}-\mathrm{TiOH}$ counterpart upon the Si-O stretching of silanol $\mathrm{OH}$. In this study the weak band at $955 \mathrm{~cm}^{-1}$ is corresponding to Si-O of ( $\left.\equiv \mathrm{Si}-\mathrm{OH}\right)$ present in the parent FSM-16. The intensity of this band enhanced by loading of different metal (Fig.4A, B, and C) may be due to the formation of an isolated Si-O-Me (Me: Fe, $\mathrm{Cu}$ and $\mathrm{Ag}$ ).

The bands at 800 and $622 \mathrm{~cm}^{-1}$ are ascribed to the symmetric vibration of Si-O-Si bridge [32] which are more pronounced for the parent FSM-16 and becomes weak with metal loading. This may be, due to the crowdness of metal oxide around Si-O-Si link, so it restricts the motion of symmetric stretching of Si-O-Si bond in the parent FSM-16.

\section{CONCLUSION}

Parent FSM-16 and its modified iron, copper and silver catalysts have well ordered hexagonal array except catalysts containing 6 and $9 \mathrm{wt} \%$ iron, a partial loss of crystallinty takes place. Also the iron species are distributed within the hoxagonal system of the FSM-16 according to the smaller iron ionic radius $(0.63 A)$ in comparison to Cu ions $(0.71 \mathrm{~A})$ and $\mathrm{Ag}$ ion $(1.08 \AA)$. Metal ions are present in the extraframwork and not incorporated in the FSM-16 silica according to the smaller value of $\alpha_{6}$ (unit cell parameter). Different metal ions are detected as $\mathrm{Fe}^{3 *}, \mathrm{Fe}^{2+}$ in the Fe/FSM-16, $\mathrm{Cu}^{2 *}, \mathrm{Cu}^{+}$in Cu/FSM-16 and $\mathrm{Ag}^{2 *}, \mathrm{Ag}^{+}$in $\mathrm{Ag} / \mathrm{FSM}-16$. Iron phases have a higher reduction temperature compared with copper and silver phases. This may be due to that the iron ions inside the hexagonai array of FSM-16 are strongly held with silica framework of the parent material. The texture properties and mesoporosity of the parent FSM-16 affected strongly by loaded transition metal dependent on the metal ionic radius of each $\mathrm{Fe}<\mathrm{Cu}<\mathrm{Ag}$. The uniform mesopores array and high surface area specified to the FSM-16 structure are attributed to the high dispersion of the supported metal species [33]. Metal phases formed during the catalyst preparation may be in the form of $\mathrm{Me}-\mathrm{O}$ or $\mathrm{MeO}-\mathrm{OH}$ and present in the certain bond linkage with the FSM-16 framework.

\section{REFERENCES}

1- S. Inagaki, Y. Fukushima, K. Kuroda, J. Chem, Sos, Chem. Commun (1993) 680.

2- C. T. Kresge, M. E. Leonewiez, W. J. Roth. J. C. Vartuli, J. S. Beck. Nature 359 (1992) 710.

3- C. Y. Chen, S. Q. Xlao, M. E. Davis, Mieropor. Mater. 4 (1995) 1

4- M. Sugioka, L. andelaluna, S. Norishita, T. Kurasaka, Catal Today $39(1997) 61$

5. M. S. Ghattas, Deita J. Sci, 25 (2001) 10.

6- J. K. A, Dapaah, Y. Uemichi, A, Ayame, H. Matsuhashi, M, Sugieka, Appl Catal A:

Gen. $187(1999) 107$

7. D. Shouro, Y. Moriya, T. Nakajima, S. Mishima, Appl. Catal,A; Gen 196 (2000) 275

8. H, T, Gomes, P, Selvam, S, E. Dapurkar, J. L. Figueiredo, J. L. Faria, Micropar, Mesopor. Mater, 86 (2005) 287.

9. W. A. Carvatho, M. Wallau, U. Schuchardt, d. Mol, Catal A: Chem 144 (1909) 91

10. T. Tsoncheva, Si Areva, M. Dimisrov, D, Paneva, I, Mitev, M, Liaden, C, Minchev,

J. Mol. Catal. A: Chem. 246 (2006) 118.

11- M, S. Ghattas, TESCE 32(2) (2005) in pres5:

12. S, Inagaki, Y.Fukushima, Mioropor. Mesopor Mater. 21 (1998) 667

13. F. Boccuzzi, A. Chiorine, M. Manzoli, D. Andreeva, Catal. Today 75 (2002) 169.

14- L. J. Kundakoovic, M. Flyzani-3tephanopeules, Appl Catal A: Gen, 193 (1909) 35

15. G. R. Maradi, M. M. Basir, A. T. Kiennemann, Catal. Commun 4 (2003) 27.

16- 5. Ribet, D. Tichit, B. Coq, B. Ducourant, F. Morato, J Solid State Chem. 142 (1999)

Deta J. Sel $2006,30,21-30$ 
17. D, song. J. Li, J. Mol. Catal. A Chem, 247 (2006) 206.

18. K. 5. W. $\operatorname{sing}$, D. H. Everett, R. A, W. Haul, L, Moscou, R. A. Pierolti, J. Reuquerol, T. Siemioniewsks, Pure Appl. Chem, 57 (1985) 603.

19. D. Zhao, Q. Huo, J. Feng, B, F. Chmelka, G. D. Stucky, J. Am. Chem. Soc, 120 (1998) 6024.

20. R.Takahashi, S. Sato, T. Sodesawa, M. Kawakita, K. Ogura, J. Phys. Chem, B: $104(2000)$ 12184.

21. J, S. beck, J. C. Vartuli, W. J, Roth, M. E. Leonowiez, C, T. Kresge, K, D, Schmitt, C T. W. Chu, D. H. Olson, E, W, sheppard, S. B. MeCullen, J. B. Higgins, J, L.

Schlenker, J. Am Chem, Soc, 114 (1992) 10834

22. M. S. Ghattas, Micropor. Mesoper. Mater, $97(2006) 107-113$.

23. M. S. Ghattas, Deita J. Sel. 25 (2001) 1.

24. M. A. Camblor, A. Corma, J. Perez-Pariente, J, Chem \$00, Chem. Commun. (1995) 557

25. K. Koyane, T. Tatsumi,"12th Zeolite Conf., Japan, (1998) 55

26. T.K Oas, K. Chaudhari, A, J. Chandwadkar, S, Sivasabker, J. Chem. Soc, Chem. Commun, (1985) 2495

27. N. K. Mal, V. Ramaswamy, S, Ganapathy, A, V. Ramaswamy, J. Chem, Soc, Chem. Commun. (1924) 1933 .

28. A. Thngara), R. Kumar, S. P. Mirajikar, P. Rataasamy, J. Catal. 130 (1991) 1.

29. P. H. P. Rao, A. V. Ramaswamy, P. Ramaswamy, J. Catal. 137 (1992) 225

30. T. Sen, M, Chatterjee, S. Siyasanker, J.Chem Soc. Chem. Commun. (1995) 207.

31. S. Schwarz, D. R. Corbin, A. J. Vega, Mater. Res. Soc, Symp Proo. $413(1996) 137$.

32. Y, Huang, Z Jiang, W. Schwieger, Micropor, Mesopar, Mater, 26 (1998) 215.

33. 2. Okamura, S. Nishiyama, S. Tsuruya, M. Nasai, J. Mole, Catal. A. Chem, 135 (1998) 133.

\title{
تأثير تحمبل المعادن على المواد وسطبة المساه مطوبة الألواح الصعانحية
}

\author{
(Me/FSM-16) \\ whet wate

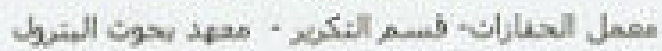

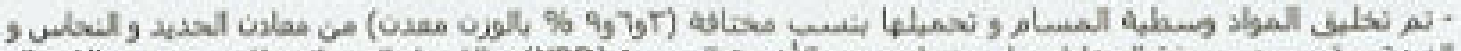

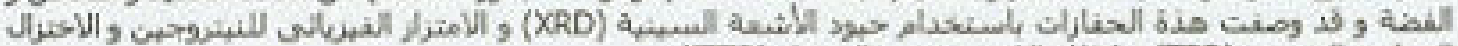

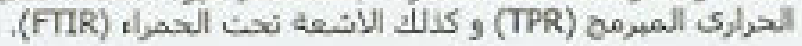

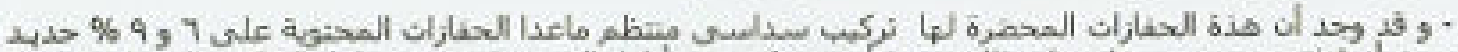

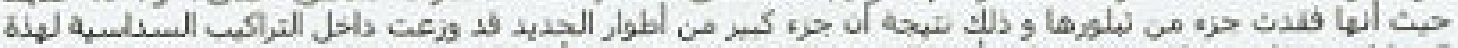

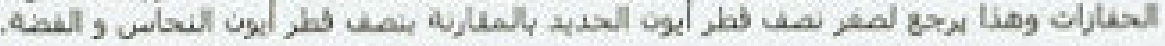

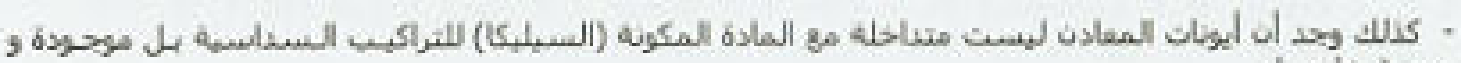
.

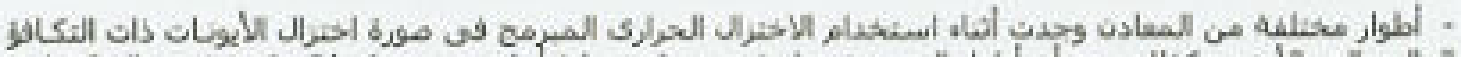

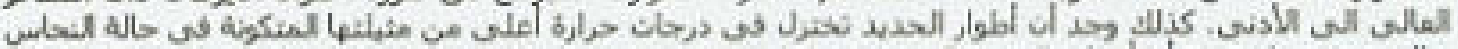

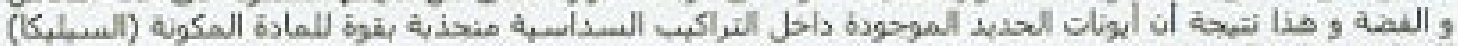

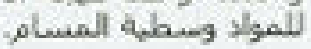

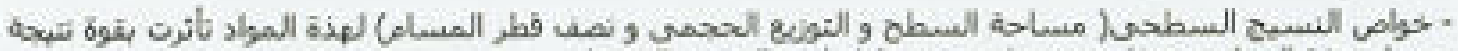

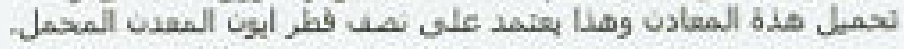

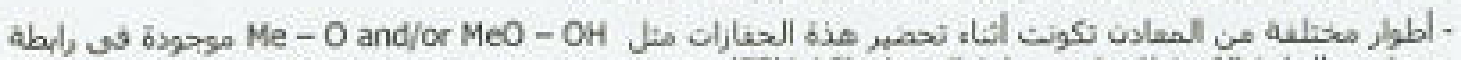

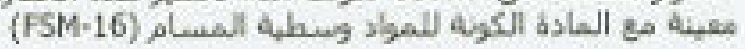

